\title{
SELEÇÃO DE ESPÉCIES DO GÊNERO Penicillium PRODUTORAS DE LIPASE LIGADA AO MICÉLIO PARA APLICAÇÃO EM HIDRÓLISE DE ÓLEOS VEGETAIS
}

\author{
Braz S. Marottia, Daniela V. Cortez ${ }^{\mathrm{a}}$, Daniel B. Gonçalves ${ }^{\mathrm{b}}$ e Heizir F. de Castro ${ }^{\mathrm{a}, *}$ \\ aDepartamento de Engenharia Química, Escola de Engenharia de Lorena, Universidade de São Paulo, 12.602-810 Lorena - SP, Brasil

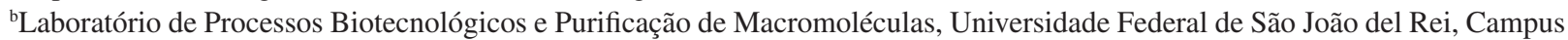 \\ Centro Oeste Dona Lindu, 35.501-296 Divinópolis - MG, Brasil
}

Recebido em 16/09/2016; aceito em 18/01/2017; publicado na web em 24/03/2017

\begin{abstract}
SCREENING OF SPECIES FROM THE GENUS Penicillium PRODUCING CELL BOUND LIPASES TO BE APPLIED IN THE VEGETABLE OIL HYDROLYSIS. Ten species of Penicillium genus isolated from different habitats were evaluated as mycelium bound lipase producers to be used in the hydrolysis of vegetable oils. Using olive oil as an inducer three species (P. italicum AT4421, $P$. janthinellum CCT3162 and $P$. purpurogenum AT2008) were able to produce lipases having high mycelium bound activities $\left(>150 \mathrm{U} \mathrm{g}^{-1}\right)$ and were further characterized in relation to their biochemical and kinetic properties and specificity using vegetable oils having majority fatty acids composition in C12:0 (coconut); C16:0 (palm); C18:1 (canola) and C18:1 (soybean). All the three lipases could enrich the medium with fatty acids according to their respective selectivity and the reaction hydrolysis was found to enhance at least three folds under ultrasonic irradiations. For P. purpurogenum lipase the highest hydrolysis degree $(66.8 \pm 0.2 \%)$ was attained with coconut oil. Both P. italicum and P. janthinellum lipases showed high selectivity for canola oil, resulting in hydrolysis degrees of $79.9 \pm 0.5 \%$ and $63.5 \pm 0.6 \%$, respectively. Analysis of the hydrolysates confirmed that the majority of the fatty acids released by $P$. italicum and $P$. janthinellum lipases was composed by oleic acid, and $P$. purpurogenum lipase the hydrolysate contained approximately $50 \%$ of lauric acid.
\end{abstract}

Keywords: lipases; Penicillium; whole-cells; hydrolysis; vegetable oils.

\section{INTRODUÇÃO}

Desde sua identificação em 1930, as lipases ainda despertam grande interesse em diversos segmentos industriais. Segundo Daiha et al., ${ }^{1}$ há uma projeção de crescimento anual na demanda mundial por estas enzimas estimada em 6,2\%, atingindo US\$ 345 milhões em 2017. Este aumento na aplicação industrial de lipases tem motivado pesquisas para o isolamento e triagem de novas fontes microbianas desta enzima.

As lipases (glicerol éster hidrolases EC 3.1.1.3) fazem parte da classe das hidrolases que atuam em ligações éster-carboxílicas e não requerem cofator. A função biológica primordial destas enzimas é catalisar a hidrólise de triacilgliceróis, entretanto, em condições em que a disponibilidade de água no meio é reduzida, a maioria é capaz de catalisar reações reversas como esterificação e transesterificação (interesterificação, alcoólise e acidólise), entre outras. ${ }^{2,3}$ Essa versatilidade e adaptabilidade em diferentes solventes tem resultado no uso difundido das lipases em diversas aplicações industriais, ${ }^{4,5}$ incluindo formulação de detergentes, fabricação de aditivos alimentares, controle de pitch na indústria de papel e biocatalisadores para transformação de óleos e gorduras da indústria oleoquímica, como hidrólise de óleos vegetais. ${ }^{2}$ A hidrólise enzimática de óleos vegetais é uma alternativa ao processo químico que busca superar os inconvenientes da rota convencional (elevadas condições de temperatura $250{ }^{\circ} \mathrm{C}$ e pressão $4,83 \mathrm{mPa}$ ), visando fornecer produtos com baixo custo energético por meio da condução da reação em condições mais amenas de temperatura e pressão. ${ }^{6}$

A maioria das lipases utilizada em aplicações biotecnológicas é obtida por cultivo de microrganismos e geralmente são produtos extracelulares. Entretanto, sob determinadas condições, diversos microrganismos possuem a habilidade de reter a enzima lipase no interior

*e-mail: heizir@dequi.eel.usp.br das células ou na membrana celular, como por exemplo, alguns fungos filamentosos, que apresentam atividade lipolítica ligada ao micélio. ${ }^{3}$ Neste aspecto, a utilização de células íntegras (whole cells) em estado estacionário (resting cells) pode ser considerada como importante alternativa para a transformação de óleos. Além disto, a célula íntegra pode ser usada como suporte, evitando as etapas de extração, isolamento e purificação das enzimas de interesse, as quais são normalmente trabalhosas e contribuem para tornar o processo oneroso. ${ }^{7}$ No caso especifico da síntese de biocombustível (biodiesel), a utilização direta do micélio como biocatalisador é uma abordagem promissora, que favorece a redução do custo global do processo. ${ }^{8,9}$

Entre os microrganismos produtores de lipase, os fungos filamentosos pertencentes às várias espécies dos gêneros Aspergillus, Rhizopus, Penicillium, Mucor e Trichoderma são descritos como potenciais produtores de lipases ligadas ao micélio, podendo ser isolados de amostras de solos, fezes de animais, partes de plantas e a partir de frutos. ${ }^{3}$ Para o presente trabalho, o enfoque foi direcionado para o gênero Penicillum, considerado bom produtor de lipase, contando com aproximadamente 30 espécies já relatadas na literatura com habilidade de produzir esta enzima com diferentes propriedades e especificidades. ${ }^{10}$ Adicionalmente, enzimas como Lipase G Amano 50 produzida pela espécie $P$. camemberti e lipase $\mathrm{R}^{\circledR}$ Amano produzida pela espécie $P$. roqueforti estão disponíveis comercialmente, encontrando diversas aplicações em biocatálise. ${ }^{11,12}$ Entretanto, ainda são escassos os trabalhos de pesquisa que reportam o uso de lipases de Penicillium, na forma de células íntegras, como biocatalisadores. Lima et al. ${ }^{13}$ por exemplo, demonstraram a potencialidade de aplicação de células íntegras de $P$. citrinum imobilizadas em poliuretano para mediar reações de hidrólise de óleos vegetais ricos em ácidos graxos poli-insaturados, como óleo de soja.

Para o desenvolvimento deste estudo foram avaliadas dez espécies do gênero Penicillium quanto ao potencial de produção de lipases ligadas ao micélio visando sua posterior utilização na 
produção de concentrados de ácidos graxos livres a partir de diferentes óleos vegetais. As espécies foram isoladas no campus da Universidade Federal de Viçosa (Minas Gerais) a partir de diferentes habitats e algumas delas avaliadas quanto à atividade de pectinase, ${ }^{14}$ entretanto, ainda não foram exploradas como fonte de produção de lipases. Além de $P$. citrinum, $P$. camembertii e $P$. oxalicum, dentre outras conhecidas como fontes de lipase, três espécies produtoras de hidrolases, mas sem relato de potencial para produção de lipases, também foram estudadas ( $P$. italicum, $P$. janthinellum, $P$. purpurogenum). As lipases selecionadas foram caracterizadas quanto às propriedades bioquímicas e cinéticas e aplicadas na hidrólise de óleos vegetais contendo diferentes composições em ácidos graxos, o que permitiu determinar a especificidade das lipases em relação aos ácidos graxos.

Aliada ao benefício do uso de biocatalisador, a ultrassonicação em baixa frequência (10-60 kHz) tem sido utilizada como uma forma de acelerar a velocidade de reações, por exemplo, pelo aumento da miscibilidade entre os reagentes (emulsão de líquidos imiscíveis) e a redução nas limitações de transferência de massa. ${ }^{15,16}$ Ao promover uma melhor homogeneização do meio reacional composto por fases distintas, em detrimento de elevada agitação mecânica, a irradiação ultrassônica auxilia na formação de maior área interfacial óleo/água, requisito essencial para atividade plena da lipase. ${ }^{17,18}$ Baseando-se em dados da literatura que sugerem o favorecimento do grau de hidrólise de óleos vegetais por lipases de diferentes fontes, em reação assistida pela irradiação ultrassônica, ${ }^{15,19,20}$ no presente estudo foi também avaliado o efeito deste sistema que proporciona estabilidade do meio emulsificado, sobre o processo de hidrólise dos óleos vegetais específicos para a atuação de cada lipase selecionada.

\section{PARTE EXPERIMENTAL}

\section{Microrganismos}

As espécies de Penicillium foram isoladas de diferentes habitats no campus da Universidade Federal de Viçosa (Viçosa-MG) pelo Dr. James J. Muchovej do Departamento de Fitopatologia e identificadas/catalogadas no Banco de Culturas do Laboratório de Processos Biotecnológicos e Purificação de Macromoléculas da Universidade Federal de São João del Rei, Campus Centro Oeste (DivinópolisMG). Para este estudo, foram avaliados: $P$. janthinellum CCT3162, $P$. chrysogenum PC2006, P. camemberti AT4461, P. charlesi AT4752, $P$. oxallicum RT1778, P. italicum AT4421, P. brevicompactum AT4457, $P$. citrinum CCT3281, $P$. purpurogenum AT2008 e $P$. roqueforti AT0062. Os fungos foram conservados em tubos de ensaio contendo meio BDA (Batata Dextrose Agar - Difco) sob refrigeração a $4{ }^{\circ} \mathrm{C}$, sendo repicados a cada dois meses.

\section{Reagentes}

Para o presente estudo foram utilizados peptona da marca Himedia $^{\circledR}$, nitrato de sódio P.A. e sulfato de magnésio hepta-hidratado P.A., ambos da marca Vetec ${ }^{\circledR}$. Acetona P.A. (99,5\% de pureza), ácido nítrico (65\% pureza), hidróxido de potássio (85\% de pureza) e ácido fosfórico ( $85 \%$ de pureza) foram adquiridos da Cromoline ${ }^{\circledR}$. Fosfato de potássio monobásico anidro P.A., clorofórmio (99,8\% de pureza) e ácido acético glacial P.A. (99,7\% de pureza), adquiridos da marca Synth ${ }^{\circledR}$ e trifluoreto de boro em solução de metanol (10\%), da Fluka Analytical ${ }^{\circledR}$. Como fonte de carbono para crescimento dos fungos foi utilizado azeite de oliva da marca Carbonell ${ }^{\circledR}$ adquirido em mercado local. Os óleos vegetais avaliados nas reações de hidrólise foram adquiridos de diversos fornecedores, sendo o óleo de coco $\left(\right.$ Frescoco $\left.{ }^{\circledR}\right)$, o óleo de canola $\left(\right.$ Purilev $\left.^{\circledR}\right)$ e o óleo de soja $\left(\right.$ Soya $\left.{ }^{\circledR}\right)$ provenientes de mercados locais, o óleo de palma foi gentilmente doado pela Agropalma (Companhia Refinadora da Amazônia) e o óleo de macaúba (polpa) foi adquirido da Associação de Pequenos Trabalhadores Rurais de Riacho D'antas. As composições dos óleos vegetais são apresentadas na Tabela 1 .

\section{Seleção das espécies de Penicillium produtoras de lipase ligada ao micélio}

Os cultivos foram realizados em frascos Erlenmeyer de 250 $\mathrm{mL}$ contendo $100 \mathrm{~mL}$ de meio composto por peptona $\left(70 \mathrm{~g} \mathrm{~L}^{-1}\right)$, $\mathrm{NaNO}_{3}\left(1 \mathrm{~g} \mathrm{~L}^{-1}\right), \mathrm{KH}_{2} \mathrm{PO}_{4}\left(1 \mathrm{~g} \mathrm{~L}^{-1}\right), \mathrm{MgSO}_{4} \cdot 7 \mathrm{H}_{2} \mathrm{O}\left(0,5 \mathrm{~g} \mathrm{~L}^{-1}\right)$, sendo todos previamente autoclavados a $121{ }^{\circ} \mathrm{C}$ por $15 \mathrm{~min}$, e como fonte de carbono, foi utilizado óleo de oliva $\left(30 \mathrm{~g} \mathrm{~L}^{-1}\right)$, o qual foi adicionado posteriormente ao meio sob condições assépticas. ${ }^{9}$ Os frascos foram inoculados com aproximadamente $1 \times 10^{6}$ esporos, determinados por contagem em câmara de Neubauer, e em seguida, incubados por $72 \mathrm{~h}$ a $30^{\circ} \mathrm{C}$ sob agitação orbital a $180 \mathrm{rpm}$. Ao final do cultivo, a biomassa foi separada do meio por filtração a vácuo, sendo, em seguida, lavada com água para remoção de compostos residuais solúveis e acetona para remoção do azeite remanescente. A umidade da biomassa foi aferida diretamente em uma balança de secagem acoplada com lâmpada de infravermelho (Marte ID 50) até obtenção de massa constante.

Como controle negativo, foi preparado frasco Erlenmeyer de $250 \mathrm{~mL}$ contendo $100 \mathrm{~mL}$ de meio de cultivo ausente de esporos, o qual foi incubado nas mesmas condições utilizadas para a obtenção das biomassas.

Nesta etapa foram quantificadas a concentração celular, em termos de grama de biomassa formada (base seca) por litro de meio, e as atividades hidrolíticas da biomassa (lipase ligada ao micélio) e do caldo fermentado (lipase extracelular), determinadas pelo método

Tabela 1. Composição em ácidos graxos dos diferentes óleos vegetais ${ }^{8,21-23}$

\begin{tabular}{|c|c|c|c|c|c|}
\hline \multirow{2}{*}{ Ácido graxo (\% em massa) } & \multicolumn{5}{|c|}{ Óleo vegetal } \\
\hline & Canola & Coco & Macaúba & Palma & Soja \\
\hline Láurico - C12:0 & - & 47,1 & - & - & - \\
\hline Mirístico - C14:0 & - & 18,8 & - & 1,2 & - \\
\hline Palmítico - C16:0 & 4,8 & 7,9 & 18,7 & 46,8 & 10,5 \\
\hline Palmitoleico - C16:1 & - & - & 4 & - & - \\
\hline Esteárico - C18:0 & 2,6 & 2,6 & 2,8 & 3,8 & 3,2 \\
\hline Oleico - C18:1 & 60,0 & 6,1 & 53,4 & 37,6 & 22,3 \\
\hline Linoleico - C18:2 & 21,4 & 1,6 & 17,7 & 10,5 & 54,5 \\
\hline Linolênico - C18:3 & 7,8 & - & 1,5 & - & 8,3 \\
\hline
\end{tabular}


de hidrólise do azeite de oliva, de acordo com metodologia descrita por Carvalho et al. ${ }^{8}$ Todos os ensaios foram realizados em triplicata.

\section{Determinação das propriedades bioquímicas e cinéticas das lipases ligadas ao micélio das espécies de Penicillium selecionadas}

As propriedades bioquímicas e cinéticas das lipases das espécies selecionadas na etapa anterior foram determinadas adotando o método de dosagem de atividade hidrolítica, ${ }^{24}$ verificando a influência do $\mathrm{pH}$ (tampão fosfato $100 \mathrm{mmol} \mathrm{L}^{-1} \mathrm{em} \mathrm{pH}$ na faixa de 5,5 a 8,0), temperatura $\left(30\right.$ a $\left.60^{\circ} \mathrm{C}\right)$ e concentração de substrato $(10$ a $60 \%$ de azeite de oliva, correspondendo a concentrações em ácidos graxos variando entre 372 a $2232 \mathrm{mmol} \mathrm{L}^{-1}$ ). A atividade hidrolítica de cada lipase foi quantificada nesses substratos, de acordo com o método de hidrólise do azeite de oliva, nas condições de $\mathrm{pH}$ e temperatura previamente estabelecidas. As constantes cinéticas de Michaelis-Menten $\left(\mathrm{K}_{\mathrm{m}}\right)$ e a velocidades máxima de reação $\left(\mathrm{V}_{\max }\right)$ foram calculadas de acordo com o modelo proposto por Lineweaver-Burk, utilizando o software Origin Pro $8^{\circledR}$.

A estabilidade térmica das lipases ligadas ao micélio também foi avaliada, em termos da constante de inativação $\left(\mathrm{k}_{\mathrm{d}}\right)$ e do tempo de meia-vida $\left(t_{1 / 2}\right)$. Para estes ensaios, suspensões constituídas por 0,1 g de biomassa (base seca) solubilizada em $5 \mathrm{~mL}$ de solução tampão fosfato $\left(100 \mathrm{mmol} \mathrm{L}^{-1}, \mathrm{pH} \mathrm{7,0)}\right.$ foram incubadas durante $150 \mathrm{~min}$ em banho termostatizado a $50^{\circ} \mathrm{C}$, com retiradas de amostras a cada $30 \mathrm{~min}$, seguidas do resfriamento imediato em banho de gelo. Em seguida, as atividades residuais das lipases foram quantificadas pelo método de hidrólise do azeite de oliva a $37^{\circ} \mathrm{C}$ em tampão fosfato (100 mmol L-1 $\mathrm{pH} 7,0)$. Os tempos de meia-vida foram calculados pelo método de ajuste exponencial. ${ }^{24}$

\section{Reações de hidrólise de óleos vegetais}

Nesta série de ensaios foram avaliados óleos vegetais contendo composição diferenciada em ácidos graxos, conforme descrito na Tabela 1. As lipases previamente selecionadas foram utilizadas para conduzir reações de hidrólise de $50 \mathrm{~mL}$ do substrato contendo $25 \%$ dos diferentes óleos em solução tampão fostato $\left(100 \mathrm{mmol} \mathrm{L}^{-1}, \mathrm{pH}\right.$ $7,0)$. O substrato foi preparado pela adição direta do agente emulsificante goma arábica $\left(3 \% \mathrm{~m} \mathrm{v}^{-1}\right)$ aos óleos e as reações foram realizadas em reatores encamisados de $100 \mathrm{~mL}$ com agitação mecânica (300 $\mathrm{rpm}$ ) a $40{ }^{\circ} \mathrm{C}$ por um período máximo de $24 \mathrm{~h}$, empregando quantidade suficiente de micélio para resultar em atividade hidrolítica para atender a relação fixa de 400 unidades de atividade por grama de óleo. O monitoramento das reações foi efetuado por retiradas periódicas de amostras de $0,5 \mathrm{~g}$ do meio reacional para determinação dos ácidos graxos liberados por titulação volumétrica com solução de $\mathrm{KOH}$ 0,020 $\mathrm{mol} \mathrm{L}^{-1}$, utilizando fenolftaleína como indicador.

Testes adicionais de hidrólise foram efetuados sob irradiação de ondas ultrassônicas utilizando apenas os óleos selecionados de acordo com a especificidade de cada lipase. Estes ensaios foram conduzidos em substratos contendo 25,35 e $50 \%$ do óleo selecionado em frasco Erlenmeyer de $125 \mathrm{~mL}$ imerso em banho ultrassônico (Unique Ultrassonic Cleaner ${ }^{\circledR}$ ) controlando o modulador de frequência em 40 $\mathrm{kHz}$ e potência de $132 \mathrm{~W}$ por um período máximo de $8 \mathrm{~h}$, mantendo também fixa a temperatura em $40{ }^{\circ} \mathrm{C}$. Os ensaios foram efetuados em duplicatas.

\section{Separação e purificação do hidrolisado}

Ao hidrolisado obtido foram adicionados $90 \mathrm{~mL}$ de clorofórmio e $25 \mathrm{~mL}$ de ácido acético glacial, sob agitação por um período de 10 min. Em seguida, todo o meio reacional foi lavado com água destilada e posteriormente transferido para um funil de decantação para a separação das fases. ${ }^{21} \mathrm{~A}$ fase clorofórmica contendo ácidos graxos livres foi esterificada com metanol, segundo metodologia AOCS, ${ }^{25}$ utilizando como catalisador $\mathrm{BF}_{3}$.

\section{Métodos analíticos}

\section{Atividade hidrolítica}

As atividades enzimáticas do micélio e dos filtrados foram determinadas pelo método de hidrólise do azeite de oliva, conforme metodologia descrita por Carvalho et al. ${ }^{8} \mathrm{O}$ substrato foi preparado pela emulsão de $10 \mathrm{~mL}$ de azeite de oliva e $90 \mathrm{~mL}$ de goma arábica a $3 \%\left(\mathrm{~m} \mathrm{v}^{-1}\right)$. Em frascos Erlenmeyer de $125 \mathrm{~mL}$ foram adicionados $5 \mathrm{~mL}$ de substrato, $4 \mathrm{~mL}$ de solução tampão fosfato de sódio (100 mmol L-1, pH 7,0) e $0,1 \mathrm{~g}$ de biomassa (massa seca) ou $0,5 \mathrm{~g}$ do caldo fermentado. Os frascos foram incubados a $37^{\circ} \mathrm{C}$ por $10 \mathrm{~min}$, em banho termostatizado com agitação. Após o período de incubação, a reação foi interrompida pela adição de $10 \mathrm{~mL}$ de uma mistura de acetona, etanol (1:1). Os ácidos graxos liberados foram titulados com solução de $\mathrm{KOH} \mathrm{0,020} \mathrm{mol} \mathrm{L}^{-1}$, utilizando fenolftaleína como indicador. Uma unidade de atividade foi definida como a quantidade de enzima que libera $1 \mu \mathrm{mol}$ de ácido graxo por minuto de reação, nas condições do ensaio. As atividades foram expressas em $\mathrm{U} \mathrm{g}^{-1}$.

\section{Grau de hidrólise}

A concentração de ácidos graxos formados nas reações de hidrólise foi determinada por titulação volumétrica da amostra com solução de $\mathrm{KOH}\left(0,020 \mathrm{~mol} \mathrm{~L}^{-1}\right)$, utilizando fenolftaleína como indicador. O grau de hidrólise foi calculado, conforme expresso na Equação 1. ${ }^{26}$

Grau de hidrólise $(\%)=\frac{(V a-V b) \times M_{K O H} \times 10^{-3} \times M M_{\text {óleo }}}{m \times f} \times 100$

Em que: $\mathrm{Va}=$ volume de $\mathrm{KOH}$ gasto pela amostra $(\mathrm{mL}) ; \mathrm{Vb}=$ volume de $\mathrm{KOH}$ gasto pelo controle $(\mathrm{mL}) ; \mathrm{M}_{\mathrm{KOH}}=$ molaridade do $\mathrm{KOH}$ utilizado $\left(0,020 \mathrm{~mol} \mathrm{~L}^{-1}\right) ; \mathrm{MM}=$ massa molar média dos ácidos graxos no óleo vegetal avaliado $\left(\mathrm{g} \mathrm{mol}^{-1}\right), \mathrm{m}=$ massa da amostra $(\mathrm{g})$ e f = fração de óleo usada.

\section{Determinação dos ésteres de metila}

A composição em ácidos graxos foi determinada como ésteres metílicos de ácidos graxos (FAME) empregando cromatografia gasosa, segundo método oficial Ce 1-62 da American Oil Chemists' Society (AOCS, 2004). A análise foi realizada em cromatógrafo Varian CP 3800 equipado com um auto-injector (CP 8410) e um detector de ionização de chama (FID). As condições utilizadas foram: coluna capilar TR FAME (30 m de comprimento, 0,25 mm de diâmetro interno e $0,25 \mu \mathrm{m}$ de espessura), gás de hélio como fase móvel a uma taxa de fluxo de 1,0 mL/min e injeção de amostra de $1 \mu \mathrm{L}$. A temperatura do forno foi mantida a $50{ }^{\circ} \mathrm{C}$ durante $1 \mathrm{~min}$, aumentada para $150^{\circ} \mathrm{Ca} 15^{\circ} \mathrm{C} / \mathrm{min}$, seguido do aumento para $180^{\circ} \mathrm{Ca} 2{ }^{\circ} \mathrm{C} / \mathrm{min}$ e depois para $250{ }^{\circ} \mathrm{C} \mathrm{a} 15^{\circ} \mathrm{C} / \mathrm{min}$ e mantida durante $5 \mathrm{~min}$. As temperaturas do detector e do injetor foram ajustadas a 250 e $200{ }^{\circ} \mathrm{C}$, respectivamente. A identificação dos ésteres metílicos foi realizada comparando-se os tempos de retenção com padrões FAME (Sigma) e a quantificação foi realizada por normalização de áreas calculadas pelo software Galaxie Chomatography Data System version 1.9.

\section{RESULTADOS E DISCUSSÃO}

\section{Seleção dos fungos produtores de lipase ligada ao micélio}

O trabalho experimental foi inicialmente direcionado à seleção das espécies do gênero Penicillium com maior potencial de produzir 
lipase ligada ao micélio. A Tabela 2 apresenta os valores médios de biomassa formada (base seca) e das atividades hidrolíticas. De maneira geral, todos os fungos apresentaram crescimento regular ao final de $72 \mathrm{~h}$, nas condições de cultivo utilizadas, alcançando concentrações de biomassa variando entre 4,8 $\pm 1,4$ a $34,1 \pm 2,7 \mathrm{~g} \mathrm{~L}^{-1}$ (base seca), correspondendo aos fungos $P$. oxalicum e $P$. italicum, respectivamente. As espécies $P$. chrysogenum, $P$. roqueforti e $P$. charlesi apresentaram crescimento celular similares, alcançando valores máximos da ordem de $16 \mathrm{~g} \mathrm{~L}^{-1}$.

Em relação à atividade de lipase a partir da biomassa, foi observada uma ampla faixa de variação dentre as espécies avaliadas, além disto, os baixos valores de atividade nos filtrados $\left(\leq 28 \mathrm{U} \mathrm{g}^{-1}\right)$ sugerem que as condições avaliadas permitiram a retenção da atividade da lipase ligada ao micélio. O maior valor de atividade foi observado para $P$. italicum $\left(\approx 200 \mathrm{U} \mathrm{g}^{-1}\right)$ e o menor para $P$. oxallicum e $P$. chrysogenum $\left(\approx 50 \mathrm{U} \mathrm{g} \mathrm{g}^{-1}\right)$. Os resultados ainda mostram que as condições experimentais avaliadas não foram satisfatórias para o crescimento e a atividade hidrolítica para a espécie $P$. oxallicum.

Ainda de acordo com a Tabela 2, verifica-se que as quatro espécies que apresentaram atividades hidrolíticas no micélio superiores a $170 \mathrm{U} \mathrm{g}^{-1}$, P. roqueforti $\left(186,9 \mathrm{U} \mathrm{g}^{-1}\right)$, P. janthinellum $\left(171,1 \mathrm{U} \mathrm{g}^{-1}\right)$, P. purpurogenum (170,3 $\left.\mathrm{U} \mathrm{g}^{-1}\right)$ e P. italicum $\left(199,3 \mathrm{U} \mathrm{g}^{-1}\right)$, também forneceram baixos valores de atividade no filtrado $\left(20 \mathrm{U} \mathrm{g}^{-1}\right)$, resultando em relações entre as atividades hidrolíticas do micélio e extracelular maiores que 7.

Estas espécies foram consideradas como potencias fontes de lipase para dar sequência ao estudo, entretanto, a espécie $P$. roqueforti não foi incluída em função de sua disponibilidade comercial. ${ }^{10}$ Além disso, não existem relatos na literatura de produção de lipases a partir das espécies $P$. janthinellum, $P$. italicum e $P$. purpurogenum, justificando a motivação desse estudo na busca de novas fontes potencias de lipases ligadas ao micélio.

\section{Propriedades bioquímicas e cinéticas das lipases ligadas ao micélio}

\section{Influência das variáveis pH e temperatura sobre a atividade das lipases selecionadas}

A Figura 1 apresenta os perfis de atividade obtidos com a variação do pH do meio (A) e da temperatura de reação (B). Com relação a influência do $\mathrm{pH}$, verifica-se inicialmente que nas condições experimentais utilizadas, todas as enzimas apresentaram atividade máxima em pH 7,0 (Figura 1A). O aumento da acidez $(\mathrm{pH}<7,0)$ do meio promoveu decréscimo da atividade com efeito mais pronunciado para as lipases de $P$. janthinellum e $P$. purpurogenum, entretanto, todas as enzimas retiveram cerca de $60 \%$ da atividade em $\mathrm{pH} 5,5$ $\left(\approx 115 \mathrm{U} \mathrm{g}^{-1}\right)$. Ainda segundo a Figura 1A, nota-se que as lipases de $P$. italicum e de $P$. purpurogenum foram menos influenciadas pela elevação do $\mathrm{pH}(>7,0)$ apresentando redução de aproximadamente 25 a 40\%, respectivamente, em relação a atividade considerada como parâmetro referencial em $\mathrm{pH}$ 7,0 ( $P$. italicum $=197,3 \pm 4,2 \mathrm{U} \mathrm{g}^{-1} \mathrm{e} P$. purpurogenum $\left.=170,3 \pm 8,5 \mathrm{U} \mathrm{g}^{-1}\right)$.

A lipase de $P$. janthinellum, por outro lado, teve redução de atividade mais acentuada com a elevação da basicidade do meio da ordem de $65 \%$ em pH 8,0 em relação ao parâmetro referencial em pH 7,0 ( $P$. janthinellum $\left.=171,1 \pm 8,1 \mathrm{U} \mathrm{g} \mathrm{g}^{-1}\right)$. Os resultados do presente estudo são similares aos obtidos por Costa e Peralta, ${ }^{27}$ referentes à produção de lipase a partir do extrato livre de células de Penicillium wortmanii. Os autores observaram maior atividade catalítica de lipase na faixa de $\mathrm{pH}$ de 6,0 a 8,0, decrescendo em 50\% com o aumento da acidez ou da basicidade do meio. Ao avaliarem o efeito do $\mathrm{pH}(4,5$ a 9,0$)$ sobre a atividade da lipase de $P$. citrinum em extrato livre de células, ${ }^{28}$ observaram máxima atuação em $\mathrm{pH} 7,0$ com decréscimo quando utilizado $\mathrm{pH}$ abaixo ou acima deste valor. Entretanto, a imobilização das células pode auxiliar na retenção da atividade hidrolítica ligada ao micélio com a alteração do $\mathrm{pH}$ do meio. Ao imobilizar micélios de $P$. citrinum em espuma de poliuretano, Lima et al. ${ }^{13}$ observaram atividade hidrolítica máxima em $\mathrm{pH} 8,0$, com decréscimo de apenas $10 \%$ quando o $\mathrm{pH}$ do substrato foi alterado para 8,5. Em seu estudo, Maliszewska e Mastalerz ${ }^{28}$ observaram redução da atividade catalítica da lipase de $P$. citrinum em $20 \%$ quando o $\mathrm{pH}$ foi aumentado de 7,0 para 8,0 e em torno de $10 \%$ com o acréscimo do $\mathrm{pH}$ de 8,0 para 8,5 .

Tendo verificado que as atividades mais elevadas foram obtidas em pH 7,0, foram realizados ensaios para a determinação a influência da temperatura na atuação das enzimas (Figura 1B). Nota-se, nas condições experimentais adotadas no presente estudo, que a lipase de P. italicum apresentou o valor mais elevado de atividade hidrolítica quando adotada a faixa de temperatura entre 40 a $45{ }^{\circ} \mathrm{C}$. $P$. purpurogenum e $P$. janthinellum, por outro lado, apresentaram atividades máximas à $40^{\circ} \mathrm{C}$. Verifica-se ainda na Figura $1 \mathrm{~B}$ que a lipase de $P$. italicum apresentou melhor atuação na faixa de temperatura avaliada, uma vez que o decréscimo da atividade catalítica (aproximadamente $10 \%$ ) foi inferior ao demonstrado pelas demais espécies, as quais foram fortemente afetadas pelo aumento da temperatura de incubação superior a $40{ }^{\circ} \mathrm{C}$ (decréscimos superiores a $70 \%$ ). A temperatura de $40^{\circ} \mathrm{C}$ foi, portanto, selecionada para a atuação das lipases avaliadas nas próximas etapas deste estudo. Em seu estudo, Costa e Peralta ${ }^{27}$

Tabela 2. Valores médios de concentração de biomassa celular e as atividades hidrolíticas na biomassa e no filtrado, para cada espécie de Penicillum, após cultivo de $72 \mathrm{~h}$ em meio contendo óleo de oliva como fonte de carbono

\begin{tabular}{|c|c|c|c|c|}
\hline \multirow{2}{*}{ Espécies } & \multirow{2}{*}{$\begin{array}{l}\text { Concentração de biomassa } \\
\qquad\left(\mathrm{g} \mathrm{L}^{-1}\right)\end{array}$} & \multicolumn{2}{|c|}{ Atividade $\left(\mathrm{U} \mathrm{g}^{-1}\right)$} & \multirow{2}{*}{$\begin{array}{l}\text { Relação das atividades } \\
\text { (biomassa/filtrado) }\end{array}$} \\
\hline & & Biomassa & Filtrado & \\
\hline P. brevicompactum & $13,6 \pm 2,1$ & $71,3 \pm 12,7$ & $21,0 \pm 3,3$ & 3,4 \\
\hline P. camemberti & $6,4 \pm 0,4$ & $128,9 \pm 13,9$ & $27,1 \pm 0,4$ & 4,8 \\
\hline P. charlesi & $16,5 \pm 3,0$ & $129,6 \pm 27,1$ & $23,6 \pm 2,3$ & 5,5 \\
\hline P. chrysogenum & $16,9 \pm 2,0$ & $51,1 \pm 2,5$ & $22,3 \pm 0,2$ & 2,3 \\
\hline P. citrinum & $23,8 \pm 2,1$ & $81,6 \pm 0,4$ & $25,5 \pm 5,3$ & 3,2 \\
\hline P. italicum & $34,1 \pm 2,7$ & $199,3 \pm 9,5$ & $19,1 \pm 1,0$ & 10,4 \\
\hline P. janthinellum & $12,4 \pm 2,0$ & $171,1 \pm 18,8$ & $21,8 \pm 0,4$ & 7,8 \\
\hline P. oxalicum & $4,8 \pm 1,4$ & $49,9 \pm 1,3$ & $14,7 \pm 1,1$ & 3,4 \\
\hline P. purpurogenum & $30,2 \pm 1,1$ & $170,3 \pm 17,6$ & $19,5 \pm 3,6$ & 8,7 \\
\hline P. roqueforti & $16,9 \pm 0,3$ & $186,9 \pm 27,9$ & $25,3 \pm 3,8$ & 7,4 \\
\hline
\end{tabular}



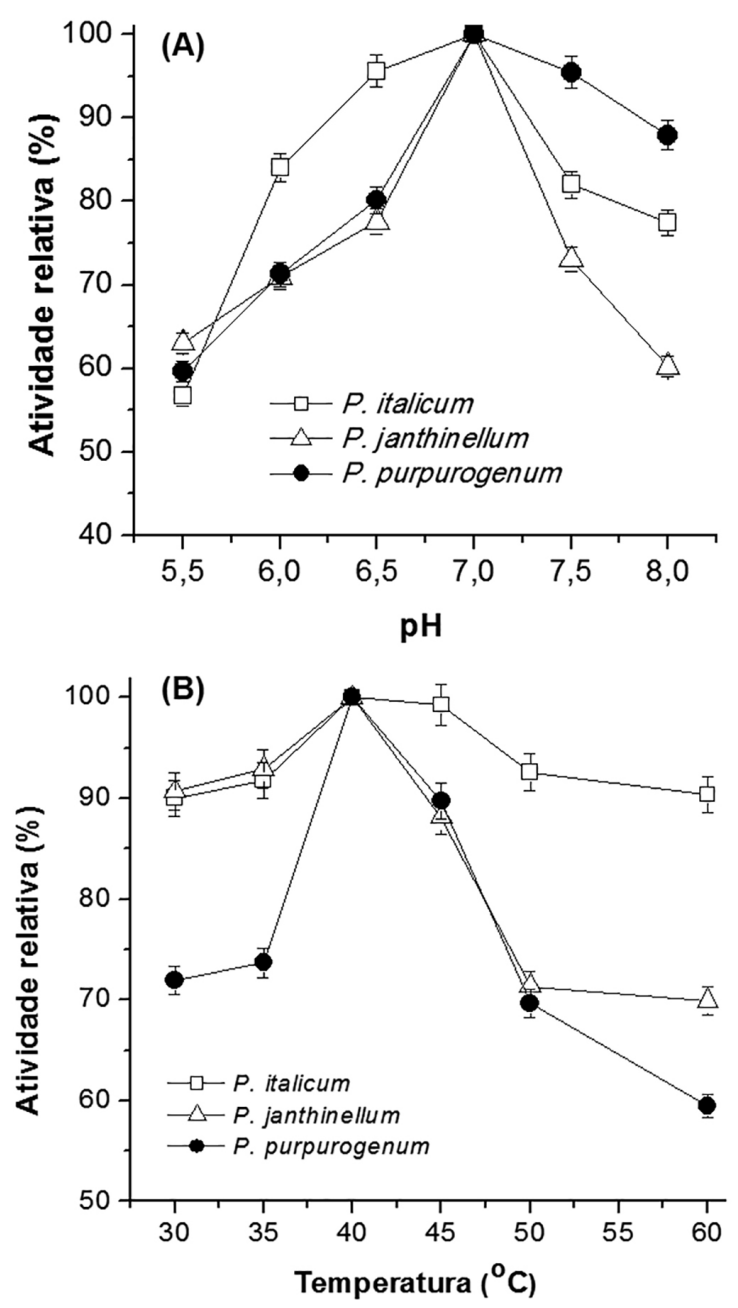

Figura 1. a) Influência do $\mathrm{pH}$ na atividade hidrolítica das lipases ligadas ao micélio de diferentes espécies do gênero Penicillium. As atividades foram determinadas em emulsão azeite de oliva (10\%) a $37^{\circ} \mathrm{C}$ e as atividades de

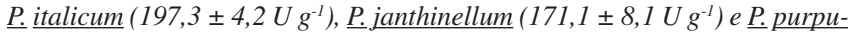
rogenum $\left(170,3 \pm 8,5 U^{-1}\right)$ foram consideradas como parâmetro referencial de $100 \%$. b) Influência da temperatura na atividade hidrolítica das lipases ligadas ao micélio de diferentes espécies do gênero Penicillium. As atividades foram determinadas em emulsão azeite de oliva (10\%) em tampão fosfato ( $\mathrm{pH}$ 7,0), as atividades de $\underline{P}$ italicum $\left(199,3 \pm 4,2 U \mathrm{~g}^{-1}\right)$, $\underline{\text { P. janthinellum }}(194,3$ $\left.\pm 5,1 \mathrm{U} \mathrm{g}^{-1}\right)$ e P. purpurogenum $\left(186,0 \pm 4,5 \mathrm{U} \mathrm{g}^{-1}\right)$ foram consideradas como parâmetro referencial de $100 \%$

verificaram que a lipase da espécie $P$. wortmani apresentou máxima atividade a $45^{\circ} \mathrm{C}$, valor próximo ao observado no presente estudo, decrescendo em torno de $50 \%$ para temperaturas mais elevadas. Mais sensível à temperatura, a lipase de $P$. citrinum apresentou máxima atividade em $30^{\circ} \mathrm{C}$, com decréscimo de 10 e $80 \%$ quando a temperatura de incubação foi aumentada de 40 para $60^{\circ} \mathrm{C}$, respectivamente..$^{28}$ Por outro lado, quando as células de $P$. citrinum foram imobilizadas em espuma de poliuretano, apresentaram atividade máxima a $35^{\circ} \mathrm{C}$, com decréscimo em torno de $15 \%$ com o aumento da temperatura para $45^{\circ} \mathrm{C} .{ }^{13}$

\section{Constantes cinéticas}

A Figura 2 apresenta as curvas de saturação do substrato para as lipases das diferentes espécies, indicando que o aumento na concentração do substrato de 372 para $1116 \mathrm{mmol} \mathrm{L}^{-1}$ resultou em incrementos significativos nas velocidades de reação para todas as preparações de lipase das espécies selecionadas.

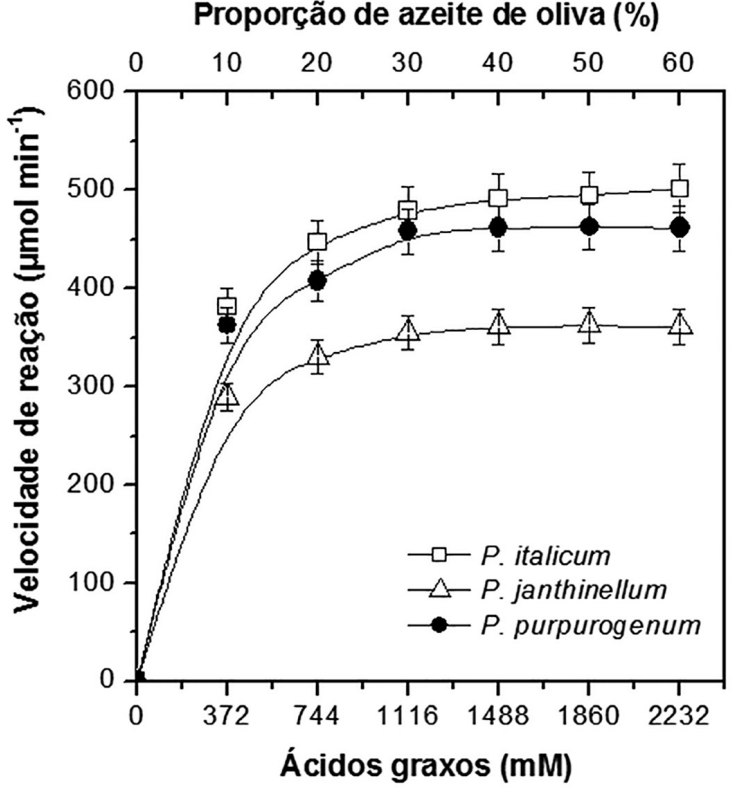

Figura 2. Influência da concentração do substrato (azeite de oliva) na atuação

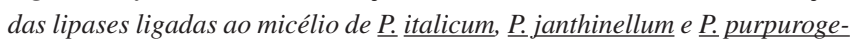
$\underline{\text { num. }}$. Condições reacionais: $40^{\circ} \mathrm{C}$, tampão fosfato de sódio $\left(100 \mathrm{mmol} \mathrm{\textrm {L } ^ { - 1 }}\right.$, pH 7,0), massa de micélio $(0,1 \mathrm{~g}), 150$ rpm e tempo reacional de $5 \mathrm{~min}$

Ainda de acordo com a Figura 2, nota-se que para valores superiores a $1488 \mathrm{mmol} \mathrm{L}^{-1} \mathrm{em}$ ácidos graxos, as atividades enzimáticas tornaram-se independentes da concentração do substrato, seguindo uma cinética do tipo Michaelis-Menten. Os valores de $K_{m}$ e $\mathrm{V}_{\max }$ foram então determinados, sendo para lipase de $P$. italicum, 151,3 mmol L ${ }^{-1}$ e $539,1 \mu \mathrm{mol} \mathrm{min}^{-1}$, respectivamente, para a lipase de $P$. janthinellum, 123,6 $\mathrm{mmol} \mathrm{L}^{-1} \mathrm{e} 387,6 \mu \mathrm{mol} \mathrm{min}^{-1}$, respectivamente e para lipase de P. purpurogenum, 141,4 $\mathrm{mmol} \mathrm{L}^{-1}$ e 493,8 $\mu \mathrm{mol} \mathrm{min}{ }^{-1}$, respectivamente. Estes resultados indicam similaridade das afinidades das lipases para o substrato azeite de oliva, que contém em sua composição $70 \%$ de ácido oleico.

\section{Estabilidade térmica}

As lipases de Penicillium são descritas como instáveis termicamente. Desta forma, para permitir comparação com os dados descritos na literatura, foram efetuados testes para determinar o tempo de meia-vida a $50^{\circ} \mathrm{C}$ das enzimas avaliadas, conforme metodologia descrita no item da parte experimental. Os perfis apresentados na Figura 3 indicam que todas as lipases apresentaram retenção de atividade superior a $90 \%$ nos primeiros 15 min e entre 50-60\% após $60 \mathrm{~min}$ de incubação. Entretanto, após esse período, as atividades residuais das lipases decresceram proporcionalmente ao tempo de incubação.

A redução mais elevada foi verificada para a lipase de $P$. italicum com inativação praticamente total $(95 \%)$ em 150 min. Em relação às lipases das demais espécies, nota-se menor redução na atividade, revelando desativação térmica menos severa. A lipase de $P$. purpurogenum foi a que apresentou maior retenção de atividade hidrolítica (30\%) ao final do tratamento térmico (150 min) quando comparada com as lipases de $P$. janthinellum e $P$. italicum, cujas atividades residuais foram inferiores a $15 \%$.

Com base nos resultados obtidos, foram determinadas as constantes de inativação térmica $(\mathrm{kd})$ e o tempo de meia-vida $\left(\mathrm{t}_{1 / 2}\right)$, para as três lipases selecionadas. A menor estabilidade térmica foi observada para lipase de $P$. italicum revelando valores de $\mathrm{kd} \mathrm{e}_{1 / 2}$ de $0,76 \mathrm{~h}^{-1} \mathrm{e}$ 0,92 h, respectivamente. As lipases de $P$. janthinellum e P. purpurogenum forneceram valores de kd correspondentes à $0,62 \mathrm{e} 0,57 \mathrm{~h}^{-1} \mathrm{e}$ de $_{1 / 2}$ da ordem de 1,17 e 1,21 h, respectivamente. Esses resultados se 


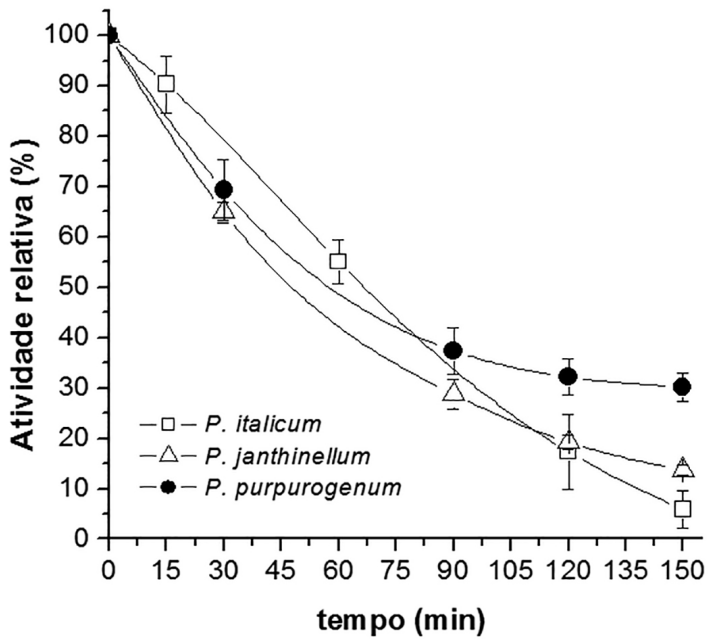

Figura 3. Estabilidade térmica $\left(50^{\circ} \mathrm{C}\right)$ das lipases ligadas ao micélio de $\underline{P} \underline{\text { italicum, }} \underline{\text { P. janthinellum e }} \underline{P}$. purpurogenum. Condições reacionais para determinação das atividades residuais: $37{ }^{\circ} \mathrm{C}$, tampão fosfato de sódio (100 mmol $\left.\mathrm{L}^{-1}, \mathrm{pH} 7,0\right)$, massa de micélio $(0,1 \mathrm{~g})$ e agitação $(150 \mathrm{rpm})$. As atividades de $\underline{P}$ italicum $\left(197,9 \pm 1,9 U \mathrm{~g}^{-1}\right)$, . janthinellum $\left(174,7 \pm 5,5 \mathrm{U} \mathrm{g}^{-1}\right)$ e $\underline{P}$ purpurogenum $\left(186,0 \pm 4,5 \mathrm{U} \mathrm{g}^{-1}\right)$ foram consideradas como parâmetro referencial de $100 \%$

comparam favoravelmente com os dados descritos na literatura para lipases microbianas, inclusive daquelas disponíveis comercialmente na forma livre, como por exemplo, Candida rugosa (Tipo VI-Sigma), que revelou tempo de meia-vida de $0,2 \mathrm{~h}$ a $50{ }^{\circ} \mathrm{C} .{ }^{24}$

Hidrólise dos óleos vegetais pelas lipases ligadas ao micélio das espécies selecionadas

Conforme descrito na Tabela 1 foram utilizados óleos vegetais com composição diferenciada em ácidos graxos como os ricos em ácido oleico (canola e macaúba), ácido láurico (coco), ácido palmítico (palma), e em ácido linoleico (soja).

A Figura 4 apresenta a formação dos ácidos graxos durante os ensaios de hidrólise dos diferentes óleos vegetais pelas lipases ligadas ao micélio de $P$. italicum, P. janthinellum e P. purpurogenum (Figura 4A, B e C, respectivamente). Os experimentos foram realizados nas condições reacionais previamente determinadas, e os resultados obtidos indicam que as hidrólises ocorreram em velocidade mais elevada nas primeiras $8 \mathrm{~h}$ de reação. A continuidade da reação por um período adicional de $18 \mathrm{~h}$ não proporcionou incrementos expressivos na concentração de ácidos graxos formados, exceto na hidrólise do óleo de canola pela lipase de P. italicum (Figura 4A), na qual o aumento do tempo reacional favoreceu a formação do produto em cerca de $30 \%$.

A Figura 5 permite efetuar uma comparação dos graus de hidrólise dos óleos vegetais alcançados pela ação das lipases avaliadas no período de $8 \mathrm{~h}$. Nota-se inicialmente, que a lipase de P. italicum foi mais efetiva na hidrólise do óleo de canola (53\%), seguido pelos óleos de palma, macaúba e coco todos na faixa de 30 a $40 \%$. O menor grau de hidrólise (20\%) foi obtido para o óleo de soja, demonstrando seletividade desta lipase por óleos compostos por elevadas proporções de ácido oleico (canola), porém baixa especificidade para óleos ricos em ácido linolênico (soja). Outro fato importante envolvendo a lipase de P. italicum foi sua atuação distinta na utilização dos óleos de canola e macaúba, apesar da similaridade da composição em ácidos graxos desses óleos (elevado teor de ácido oleico). Este comportamento pode ser atribuído ao grau de pureza dos óleos empregados, o qual interferiu na porcentagem inicial de ácidos livres no substrato. O óleo de canola de grau comercial alimentício apresenta baixo teor de acidez, enquanto o óleo de macaúba fornecido por empresa de pequeno porte apresenta elevado teor de ácido graxo livre. Desta forma, verifica-se que o óleo de macaúba em função da acidez inicial acarretou menor formação de ácidos graxos livres quando comparado ao canola.

Ao observar os resultados da hidrólise utilizando a lipase de $P$. janthinellum (Figura 5), nota-se que a enzima também foi capaz de hidrolisar todos os óleos vegetais testados, fornecendo graus de hidrólise variando entre 23 a 55\%. Apesar de possuírem composições distintas em ácidos graxos, os óleos de canola e palma, favoreceram a atuação desta lipase revelando graus de hidrólise mais elevados. Por outro lado, o menor grau de hidrólise foi alcançado utilizando óleo de coco como substrato, o qual possui elevada concentração de ácido láurico em sua composição.

Ainda com relação à atuação de lipase de $P$. janthinellum, notam-se valores intermediários de graus de hidrólise a partir dos óleos de macaúba e soja (da ordem de 35 - 40\%). Além disto, apesar da similaridade da composição do óleo de canola e macaúba (Tabela 1), a Figura 5 mostra que foram obtidos graus de hidrólise diferentes para estes substratos, em função da elevada acidez inicial do óleo de macaúba, sendo este fator relevante para a catálise, acarretando em menor atividade hidrolítica da enzima, como anteriormente constatado em relação as reações catalisadas pela lipase $P$. italicum.

A Figura 5 também apresenta os resultados de hidrólise dos óleos vegetais por lipase de $P$. purpurogenum. Observa-se que esta enzima apresentou melhor desempenho quando o óleo de coco foi utilizado, promovendo aproximadamente 50\% de hidrólise do substrato. Estes
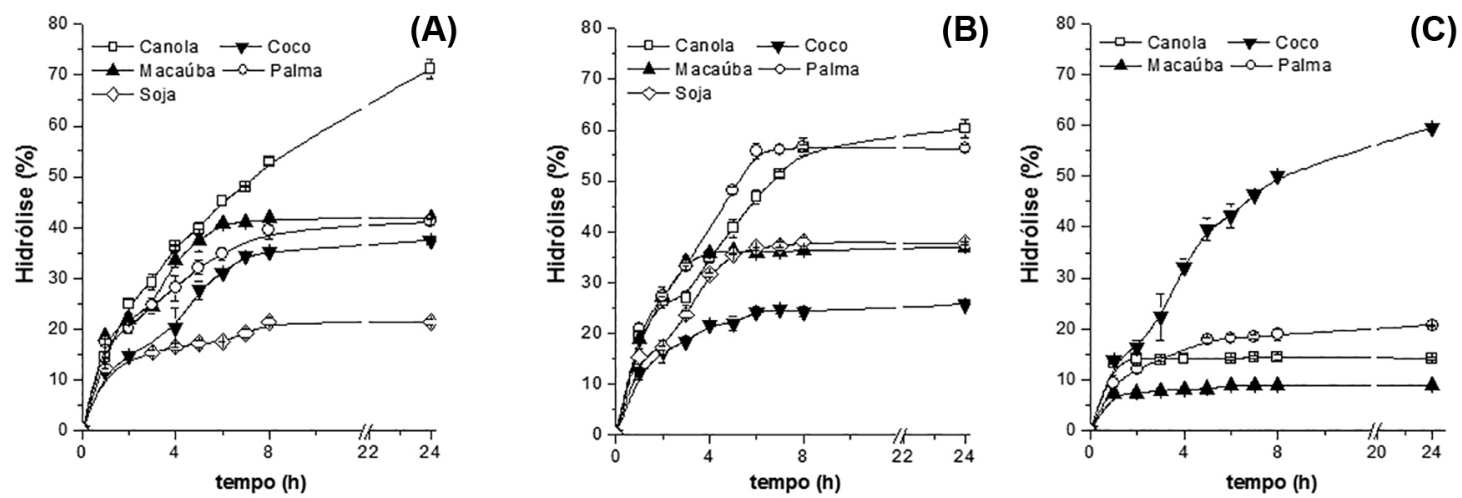

Figura 4. Formação dos ácidos graxos durante a hidrólise dos diferentes óleos vegetais pelas lipases ligadas ao micélio de $\underline{P}$ italicum (A), $\underline{P}$ janthinellum (B) $e \underline{\text { P. purpurogenum }}(\boldsymbol{C})$. Condições reacionais: $40^{\circ} \mathrm{C}$, tampão fosfato de sódio (100 mmol $\left.\mathrm{L}^{-1}, \mathrm{pH} 7,0\right)$, substrato (25\% óleo vegetal), 400 unidades de atividades por grama de óleo, agitação $300 \mathrm{rpm}$, tempo $24 \mathrm{~h}$. Os teores de ácidos graxos nos substratos no tempo inicial foram: canola $\left(15,9 \pm 0,5 \mathrm{mgKOH} \mathrm{g}^{-1}\right) ;$ coco (2,0 \pm 0,1 $\left.\mathrm{mgKOH} \mathrm{g}^{-1}\right) ;$ macaúba $\left(39,0 \pm 0,2 \mathrm{mgKOH} \mathrm{g}^{-1}\right) ;$ palma $\left(16,8 \pm 0,4 \mathrm{mgKOH} \mathrm{g}^{-1}\right) ; \operatorname{soja}\left(14,8 \pm 0,1 \mathrm{mgKOH} \mathrm{g}^{-1}\right)$ 


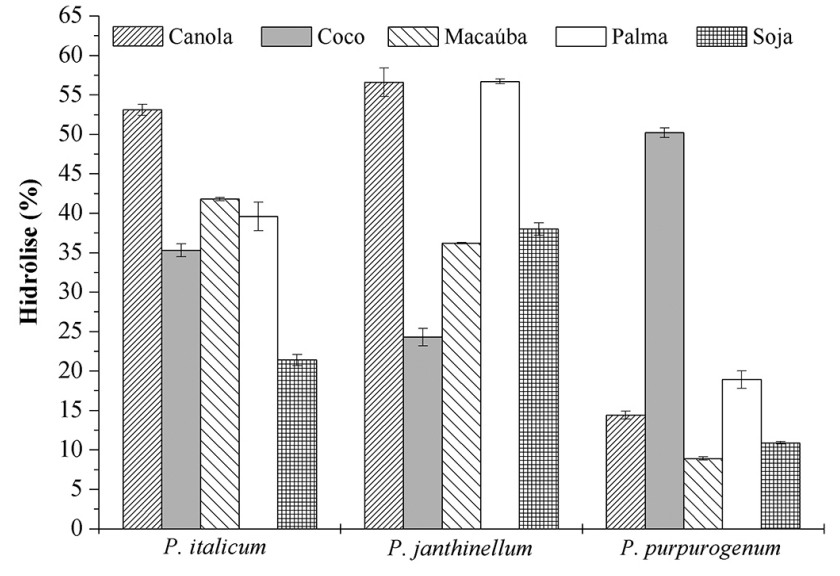

Figura 5. Grau de hidrólise dos diferentes óleos vegetais (canola, coco, macaúba, palma, soja) pelas lipases ligadas ao micélio de $\underline{P}$ italicum, $\underline{P}$. janthinellum e $\underline{P}$. purpurogenum. Condições reacionais: $40{ }^{\circ} \mathrm{C}$, tampão fosfato de sódio (100 mmol $\left.\mathrm{L}^{-1}, \mathrm{pH} 7,0\right)$, substrato (25\% óleo vegetal), 400 unidades de atividades por grama de óleo, agitação $300 \mathrm{rpm}$, tempo $8 \mathrm{~h}$

resultados sugerem que a lipase de $P$. purpurogenum possui maior especificidade por óleos compostos por ácidos graxos saturados de cadeia média, como é o caso do óleo de coco, rico em ácido láurico. Por outro lado, é possível notar que esta enzima apresentou desempenho limitado para os outros óleos vegetais avaliados (grau de hidrólise $<23 \%$ ). Segundo Padilha e Augusto-Ruiz, ${ }^{29}$ a presença de ligações duplas carbono-carbono com configuração cis em ácidos graxos resulta em dobras nas cadeias e o grupo metil terminal dos ácidos graxos, fecha-se em direção à ligação éster, o qual pode causar um obstáculo espacial para a atuação de algumas lipases. Esta configuração pode ser uma justificativa para explicar os baixos graus de hidrólise alcançados pela lipase $P$. purpurogenum em óleos vegetais contendo elevadas proporções de ácidos graxos insaturados.

Os resultados obtidos sugerem, portanto, que as lipases das espécies $P$. italicum e $P$. janthinellum apresentaram maior especificidade para o óleo de canola contendo em sua composição, ácido oleico como componente majoritário. Por outro lado, a lipase da espécie $P$. purpurogenum demonstrou elevada especificidade apenas para o ácido láurico componente majoritário do óleo de coco.

\section{Efeito da irradiação de ondas ultrassônicas}

Selecionados os óleos vegetais específicos para a atuação de cada lipase, experimentos adicionais foram conduzidos visando avaliar o efeito da irradiação de ondas ultrassônicas no meio reacional sobre o grau de hidrólise, empregando banho de ultrassom. A combinação da irradiação por ondas ultrassônicas de baixa frequência e agitação mecânica pode tornar o processo mais eficiente, favorecendo a formação da área interfacial (óleo/água) e aumentando a difusão de substratos para os sítios ativos da enzima, resultando em elevadas conversões em menor tempo..$^{17,19,20}$

A Figura 6 (A-C) mostra os perfis de hidrólise nos ensaios realizados em reator encamisado (aquecimento convencional) e em frascos Erlenmeyer imersos em banho de ultrassom. Verifica-se para todas as lipases testadas que as curvas de progresso da hidrólise apresentaram comportamento distinto, com melhor desempenho observado para as reações conduzidas sob irradiação ultrassônica.

Observa-se na Figura 6A que no sistema no sistema convencional a lipase de $P$. italicum forneceu graus de hidrólise de $56,1 \pm 0,6 \%$, enquanto no sistema em banho de ultrassom foram alcançados 79,9 $\pm 0,4 \%$, o que corresponde a um incremento de $42 \%$ na formação de ácidos graxos livres, no mesmo período de ração ( $8 \mathrm{~h})$. Esses resultados corroboram com dados reportados por Liu et al. ${ }^{30}$ que verificaram incrementos da ordem $35 \%$ na hidrólise de óleos vegetais utilizando lipases comerciais quando o sistema reacional foi irradiado com ondas ultrassônicas.

A observação da Figura 6B indica a formação de $62,0 \pm 0,6 \%$ em ácidos graxos livres pela ação da lipase de $P$. janthinellum após $5 \mathrm{~h}$ de reação sob irradiação ultrassônica, enquanto no sistema convencional foi alcançado apenas $40 \%$ de hidrólise no mesmo período, representando um incremento de aproximadamente 50\% no grau de hidrólise e redução de 3 horas no tempo global da reação.

Comparada à atuação da lipase de $P$. purpurogenum nos diferentes sistemas (Figura 6C), observa-se que em 6 h de reação o sistema irradiado com ondas ultrassônicas propiciou um aumento de $33 \%$ na produção de ácidos graxos livres, e redução de 2 horas no processo de hidrólise. Esses resultados são comparáveis aos obtidos por Waghmare e Rathod, ${ }^{20}$ os quais relataram aumento no rendimento e redução do tempo de reação na hidrólise enzimática do óleo residual de fritura usando Novozym ${ }^{\circledR} 435$ em processo assistido por ultrassom em baixa frequência de irradiação. Segundo os autores, além de reduzir a barreira de transferência de massa, a turbulência física intensa produzida pela cavitação também pode auxiliar a reorganizar corretamente o domínio catalítico ativo da enzima com substrato e a liberar o produto formado da sua superfície da biomolécula, favorecendo, portanto, a velocidade total de reação.

Desta forma, os resultados obtidos no presente estudo mostram que a aplicação de ondas ultrassônicas favoreceu as reações de hidrólise dos óleos vegetais mediadas pelas lipases ligadas ao
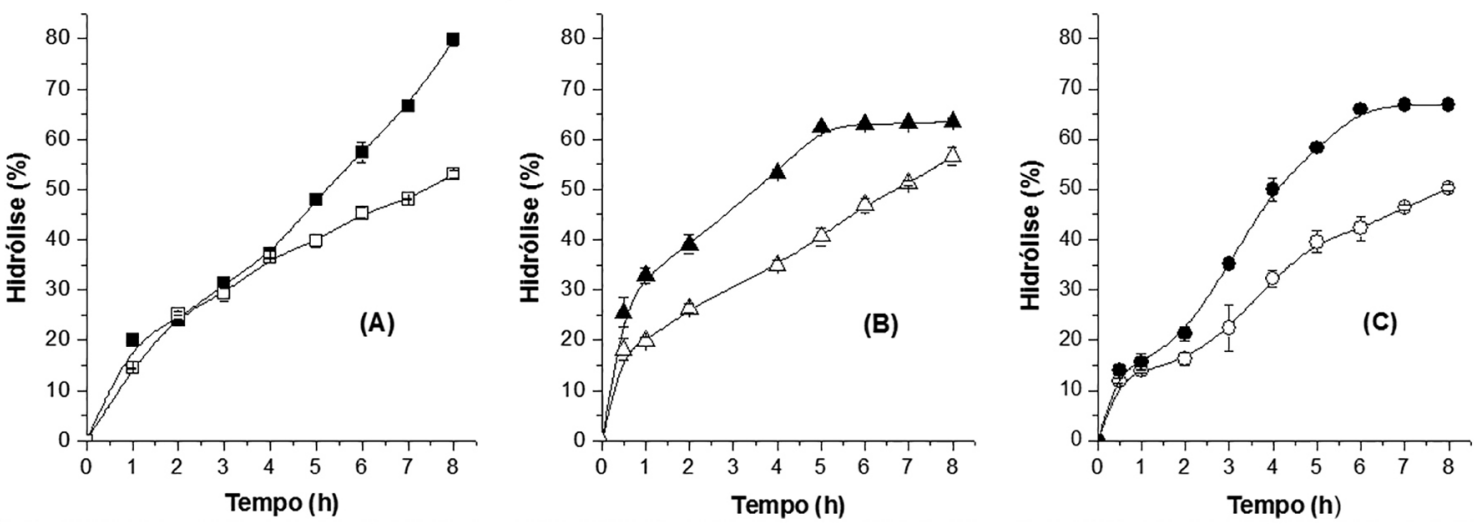

Figura 6. Perfis de hidrólises utilizando as lipases das espécies P. italicum e óleo de canola (A), P. janthinellum e óleo de canola (B) e P. purpurogenum e óleo de coco $(\boldsymbol{C})$ sob aquecimento convencional (símbolo aberto) e irradiação ultrassônica (símbolo fechado). Condições reacionais: $40^{\circ} \mathrm{C}$, tampão fosfato de sódio (100 $\mathrm{mmol} \mathrm{L}^{-1}, \mathrm{pH} 7,0$ ), substrato (25\% óleo vegetal), 400 unidades de atividades por grama de óleo, tempo $8 \mathrm{~h}$ 
micélio, aumentando a velocidade das reações e o grau de hidrólise, demonstrando ser um sistema eficiente para este tipo de aplicação.

\section{Efeito da concentração do substrato}

Estudos adicionais foram realizados para verificar a influência da concentração do substrato $(25,35,50 \%)$ na atuação das lipases das espécies selecionadas (Figura 7A-C). A razão molar de substratos para uma reação de hidrólise é dada pela quantidade de água e óleo. Uma ativação interfacial é requerida pelas lipases para sua total atividade catalítica. ${ }^{31}$

A Figura 7A mostra que a atuação da lipase de P. italicum foi visivelmente reduzida com o aumento da concentração do substrato para 35 e $50 \%$. Em elevadas concentrações de óleo a reação de hidrólise é geralmente limitada, uma vez que ocorre o fenômeno de coalescência, agrupamento de várias partículas de óleo formando grandes gotas de óleo, o que reduz drasticamente a área da interface e, por conseguinte, a velocidade de reação. ${ }^{18,31}$ Este comportamento é comumente reportado na hidrólise de óleos vegetais catalisada por lipases e pode ser também explicado pela necessidade da adsorção da enzima na interface lipídeo/água. Quanto menor a interface, menor será a quantidade de enzima adsorvida, acarretando velocidades de hidrólise mais baixas. ${ }^{18,32}$ Portanto, uma das principais dificuldades na compreensão do mecanismo da hidrólise é devido ao fato da atividade das lipases depender fortemente de como os substratos lipofílicos são apresentados à enzima, isto é, das propriedades físicas da emulsão que é necessário estabelecer. ${ }^{31,33}$ Complicações adicionais podem ocorrer a partir da mudança da área interfacial durante o curso da reação hidrolítica, devido, por exemplo, à formação de ácidos graxos livres. Consequentemente, as características físico-químicas do sistema emulsificado variam em função do tempo, resultando numa mudança da disponibilidade da interface pela enzima e de novos substratos. ${ }^{18,31}$ Em função da complexidade mencionada, a verdadeira cinética de lipases num sistema bifásico dinâmico ainda não está completamente entendida, e depende das condições reacionais, incluindo tipo e concentração de emulsificante. ${ }^{32,33}$ Para o propósito deste estudo, o desempenho das lipases das espécies selecionadas foi analisado somente quanto a influência da proporção de óleo contida na emulsão, considerando que a irradiação ultrassonora facilita a manutenção da interface lipídeo/água. ${ }^{17}$

Em relação à lipase da espécie $P$. janthinellum (Figura 7B) nota-se comportamento similar, ou seja, $25 \%$ de óleo foi a concentração na qual houve maior formação de ácidos graxos livres, entretanto, o efeito negativo do aumento da concentração do substrato foi menos acentuado do que o observado para a lipase de P. italicum. Verificase, ainda, que utilizando $50 \%$ de óleo a saturação da enzima pelo substrato ocorreu em $5 \mathrm{~h}$, fornecendo, desta forma, 39,2 $\pm 0,2 \%$ de grau de hidrólise, sendo este valor inferior ao obtido quando utilizada a concentração de $35 \%$ em 7 h de reação $(49,6 \pm 0,8 \%)$. Na atuação da lipase de $P$. purpurogenum na hidrólise do óleo de coco (Figura 7C), verifica-se que, para concentrações mais elevadas do substrato (35 e 50\%), a velocidade inicial de reação foi afetada inicialmente, entretanto, com o progresso da reação foram obtidos valores similares de ácidos graxos livres, correspondendo ao grau de hidrólise de 30\%.

Os resultados obtidos nesta série de ensaios indicam comportamentos similares das lipases em relação ao efeito da concentração do substrato, sendo constatado que a porcentagem de $25 \%$ de óleo forneceu graus de hidrólises mais elevados, enquanto proporções mais elevadas (35 e 50\%) influenciaram negativamente a atividade hidrolítica das três lipases avaliadas. Cavalcanti-Oliveira et al. ${ }^{34}$ demonstraram que na hidrólise de óleo de soja catalisada por lipase comercial de Thermomyces lanuginosus em diferentes concentrações de substrato, a enzima foi também influenciada negativamente para substratos contendo proporções mais elevadas de óleo. Segundo Chua et al. ${ }^{35}$ a inibição pelo substrato pode ocorrer em diferentes concentrações dependendo da fonte de lipase, da natureza do óleo e das condições de reação. De maneira geral, há vários registros na literatura indicando que o aumento da proporção de água do meio reacional (redução da proporção de óleo) pode favorecer incrementos da atividade devido à melhor conformação enzimática e maior área de interface. ${ }^{36,37}$

\section{Quantificação dos produtos de hidrólise}

Os produtos de hidrólise dos óleos de canola pela atuação das lipases de $P$. italicum e $P$. janthinellum e do óleo de coco pela lipase $P$. purpurogenum foram analisados por cromatografia gasosa e os resultados estão apresentados na Tabela 3. Em termos de concentrados de ácidos graxos livres, ambas as lipases das espécies $P$. italicum $e$ $P$. janthinellum foram capazes de enriquecer o meio hidrolisado com ácidos graxos insaturados provenientes do óleo de canola. A lipase da espécie P. italicum forneceu $79 \%$ de material hidrolisado e desse valor aproximadamente $68 \%$ foram ácidos graxos poli-insaturados (C18:1 e C18:2), enquanto a lipase da espécie $P$. janthinellum foi capaz de hidrolisar $63 \%$ do óleo de canola, e 53\% do material hidrolisado foi composto também pelos mesmos ácidos graxos poli-insaturados. A lipase de espécie $P$. italicum, por outro lado, promoveu a maior liberação do ácido oleico (C18:1) para o meio reacional (49\%) em relação a lipase de $P$. janthinellum (37\%).

A Tabela 3 ainda mostra que entre as lipases selecionadas, a de $P$. purpurogenum forneceu resultado distinto, tendo hidrolisado preferencialmente de ácidos graxos saturados, presentes no óleo de coco. É possível observar que dos $66 \%$ dos ácidos graxos liberados por esta lipase $53 \%$ são compostos de ácidos graxos saturados (C12:0,
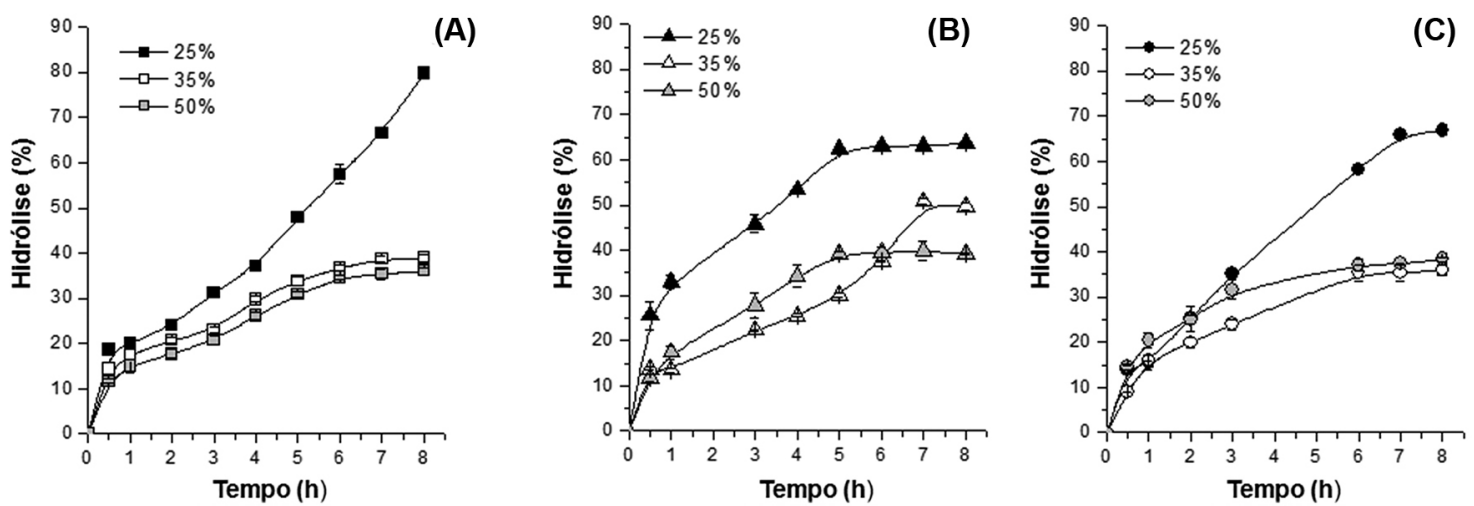

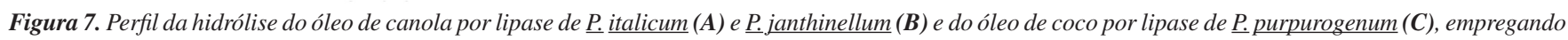
diferentes proporções (óleo:água) em reação conduzida sob as seguintes condições: irradiação ultrassônica a $40{ }^{\circ} \mathrm{C}$, tampão fosfato de sódio (100 mmol $\mathrm{L}^{-1}$, pH 7,0), substrato (25, 35 e $50 \%$ óleo vegetal), 400 unidades de atividades por grama de óleo, agitação 300 rpm, tempo $8 \mathrm{~h}$ 
Tabela 3. Composição dos concentrados de ácidos graxos obtidos nos hidrolisados dos óleos de canola e coco empregando as lipases selecionadas. Condições de hidrólise: $25 \%$ de óleo vegetal, pH 7,0 a $40{ }^{\circ} \mathrm{C}$, sob irradiação ultrassônica por $8 \mathrm{~h}$

\begin{tabular}{|c|c|c|c|c|c|c|}
\hline \multirow[b]{2}{*}{ Lipase } & \multirow{2}{*}{$\begin{array}{c}\text { Grau de } \\
\text { hidrólise (\%) }\end{array}$} & \multicolumn{5}{|c|}{ Ácidos graxos (\%) } \\
\hline & & $\begin{array}{c}\text { Láurico } \\
\text { C12:0 }\end{array}$ & $\begin{array}{c}\text { Mirístico } \\
\text { C14:0 }\end{array}$ & $\begin{array}{c}\text { Palmítico } \\
\text { C16:0 }\end{array}$ & $\begin{array}{l}\text { Oleico } \\
\text { C18:1 }\end{array}$ & $\begin{array}{c}\text { Linoleico } \\
\text { C18:2 }\end{array}$ \\
\hline P. italicum* & $79,9 \pm 0,5$ & 2,1 & 0,8 & 7,8 & 49,0 & 13,6 \\
\hline P. janthinellum* & $63,5 \pm 0,6$ & 1,2 & 0,7 & 8,1 & 37,0 & 11,9 \\
\hline P. purpurogenum $* *$ & $66,8 \pm 0,2$ & 33,9 & 14,5 & 4,7 & 1,7 & 0,4 \\
\hline
\end{tabular}

*Óleo de canola. ** Óleo de coco.

C14:0, C16:0), tendo como componente majoritário o ácido láurico (34\%), seguido por ácido mirístico com $14 \%$.

\section{CONCLUSÃO}

As espécies do gênero Penicillium descritas neste trabalho são fontes promissoras de lipase ligada ao micélio, que podem ser aplicadas em reações de hidrólise de óleos vegetais saturados ou insaturados, dependendo da espécie selecionada. Potenciais aplicações deste procedimento são as reações de hidrólises de óleos vegetais para obtenção de concentrados de ácidos graxos de alto valor agregado (ômega 6), pré-tratamento de efluentes da indústria alimentícia, e uma alternativa na utilização em reações de hidroesterificação para produção de biocombustíveis utilizando matérias-primas de baixa qualidade. Entretanto, estudos adicionais são ainda necessários visando estabelecer para cada óleo vegetal as condições que favorecem o alcance de elevados graus de hidrólise, sendo recomendado para esse propósito a metodologia de superfície de resposta.

Cabe ainda destacar que o trabalho experimental descrito neste estudo foi conduzido empregando lipases ligadas ao micélio na forma livre (biomassa com elevada atividade hidrolítica), entretanto, algumas aplicações dessas lipases podem requerer o uso na forma imobilizada em suporte adequado, como poliuretano. Esta forma alternativa de biocatalisador pode ser muito útil para condução de reações em reatores de leito fixo operando em fluxo contínuo.

\section{AGRADECIMENTOS}

À CAPES (Coordenação de Aperfeiçoamento de Pessoal de Ensino Superior) e ao CNPq (Conselho Nacional de Desenvolvimento Científico e Tecnológico), pelo apoio financeiro.

\section{REFERENCIAS}

1. Daiha, K. G.; Angeli, R.; de Oliveira, S. D.; Almeida, R. V.; PLoS One (2015), doi: 10.1371/journal.pone.0131624.

2. Singh, A. K.; Mukhopadhyay, M.; Appl. Biochem. Biotechnol. 2012, $166,486$.

3. Cortez, D. V.; de Castro, H. F.; Andrade, G. S. S.; Quim. Nova 2017, 40, 85 .

4. Anobom, C. D.; Pinheiro, A. S.; De-Andrade, R. A.; Aguieiras, E. C. G.; Andrade, G. C.; Moura, M. V.; Almeida, R. V.; Freire, D. M.; BioMed Res. Int. 2014, ID 684506.

5. Kapoor, M.; Gupta, M. N.; Process Biochem. 2012, 47, 555.

6. Goswami, D.; Basu, J.K.; De, S.; Crit. Rev. Biotechnol. 2013, 33, 81.

7. Faber, K.; Biotransformation in Organic Chemistry, $6^{\text {th }}$ ed., SpringerVerlag: Heidelberg, 2011.

8. Carvalho, A. K. F.; Faria, E. L. P.; Rivaldi, J. D.; Andrade, G. S. S.; de Oliveira, P. C.; de Castro, H. F.; Ind. Crops Prod. 2015, 67, 287.

9. Andrade, G. S. S.; Carvalho, Ana K. F.; Romero, C. M.; Oliveira, P. C.; de Castro, H. F.; Bioprocess Biosyst. Eng. 2014, 37, 2539.
10. Li, N.; Zong, M.-H.; J. Mol. Catal. B: Enzym. 2010, 66, 43.

11. Freitas, L.; Silva, G. S.; Santos, J. C.; Oliveira, P. C.; De Castro, H. F.; Eur. Food Res. Technol. 2011, 233, 743.

12. Balcão, V. M.; Malcata, F. X.; Biotechnol. Adv. 1998, 16, 309.

13. Lima, R.; Arcas, A. B.; Pereira, R. M.; de Castro, H. F.; Andrade, G. S. S.; XII Seminário Brasileiro de Tecnologia Enzimática, Caxias do Sul, Brasil, 2016. https://www.ucs.br/site/eventos/enzitec-2016/anais/, acessada em fevereiro de 2017.

14. Varavallo, M. A., Queiroz, M. V.; Lana, T. G.; Brito, A. T. R.; Gonçalves, D. B.; Araújo, E. F.; Braz. J. Microbiol. 2007, 38, 52.

15. Zenevicz, M. C.; Jacques, A.; Furigo Jr, A.; Oliveira, J. V.; de Oliveira, D.; Ind. Crops Prod. 2016, 80, 235.

16. Lerin, L.A.; Loss, R. A.; Remonatto, D.; Zenevicz, M. C.; Balen, M.; Netto, V. O.; Ninow, J. L.; Trentin, C. M.; Oliveira, J. V.; de Oliveira, D.; Bioprocess Biosyst. Eng. 2014, 37, 2381.

17. Huang, J.; Liu, Y.; Song, Z.; Jin, Q.; Liu, Y.; Wang, X. Ultrason. Sonochem. 2010, 17, 521.

18. de Castro, H. F.; Mendes, A. A.; Santos, J. C.; Aguiar, C. L.; Quim. Nova 2004, 27, 146.

19. Rokhina, E. V.; Lens, P.; Virkutyte, J.; Trends Biotechnol. 2009, 27, 298.

20. Waghmare, G. V.; Rathod, V. K.; Ultrason. Sonochem. 2016, 32, 60.

21. Freitas, L.; Bueno, T.; Perez, V. H.; Santos, J. C.; de Castro, H. F.; World J. Microbiol. Biotechnol. 2007, 23, 1725.

22. Nunes, G. F. M. Tese de Doutorado, Universidade de São Paulo, Brasil, 2011.

23. da Conceicão, L. R. V.; Carneiro, L. M.; Rivaldi, J. D.; de Castro, H. F.; Ind. Crops Prod. 2016, 89, 416.

24. Simões, A. S.; Mori, R.Y.; Faria, R.; de Castro, H. F.; Quim. Nova 2011, $34,33$.

25. AOCS; Official methods and recommended practices of the American Oil Chemists' Society, AOCS: Champaign, 2004.

26. Rooney, D.; Weatherley, L. R.; Process Biochem. 2001, 36, 947.

27. Costa, M. A. F.; Peralta R. M.; J. Basic Microbiol. 1999, 39, 11.

28. Maliszewska, I.; Mastalerz, P.; Enzyme Microbiol. Technol. 1992, 14, 190.

29. Padilha, M. E. S.; Augusto-Ruiz, M.; Cienc. Tecnol. Aliment. 2010, 30, epub. doi:10.1590/S0101-20612010005000002.

30. Liu, Y; Jin, Q.; Shan, L.; Liu, Y.; Shen, W.; Wang, X.; Ultrason. Sonochem. 2008, 15, 402.

31. Sarda, L.; Desnuelle, P.; Biochim. Biophys. Acta 1958, 30, 513.

32. Freitas, L.; Bueno, T.; Pérez, V. H.; Santos, J. C.; De Castro, H. F.; Cienc. Cult. 2006, 1, 50.

33. Brockman, H. L. Em Lipases; Borgström, B., Brockman, H. L., eds., Elsevier Science Publishers: Amsterdam, 1984. p. 1.

34. Cavalcanti-Oliveira, E. D'A.; da Silva, P. R.; Ramos, A. P.; Aranda, D. A. G.; Freire D. M. G.; Enzyme Res. 2011, ID 618692.

35. Chua; L. S.; Alitabarimansor, M.; Lee, C. T.; Mat, R.; Enzyme Res. 2012, ID 542589.

36. Chu, B. S.; Quek, S. Y.; Baharin B. S.; Food Chem. 2003, 80, 295.

37. You, L. L.; Baharin, B. S.; J. Food Lipids 2006, 13, 73. 